\title{
Human immunodeficiency and Hodgkin lymphoma
}

\author{
Gerhard Sissolak \\ Division of Clinical Haematology, Department of Internal Medicine, Faculty of Health Sciences, \\ Stellenbosch University, Tygerberg Academic Hospital, South Africa.
}

\section{Dagmar Sissolak}

Division of Clinical Haematology, Department of Internal Medicine, Faculty of Health Sciences, Stellenbosch University, Tygerberg Academic Hospital, South Africa.

\author{
Peter Jacobs \\ Division of Clinical Haematology, Department of Internal Medicine, Faculty of Health Sciences, \\ Stellenbosch University, Tygerberg Academic Hospital, South Africa. \\ University of Cape Town, South Africa. \\ College of Medicine, University of Nebraska Medical Centre, South Africa. \\ The Department of Haematology and Bone Marrow Transplant Unit, Incorporating The Searll Research \\ Laboratory for Cellular and Molecular Biology, Constantiaberg Medi-Clinic, Burnham Road, Plumstead, \\ Cape Town, South Africa. \\ Corresponding author. Address: Constantiaberg Medi-Clinic, P.O. Box 294, Plumstead 7800, Cape Town, \\ South Africa.
}

\begin{abstract}
Presentation of Hodgkin lymphoma (HL) is distinctive in the infected individual being more advanced, accompanied by B symptoms and the presence of extranodal disease particularly lymphadenopathy of the head and neck. Bone marrow involvement may be found in over $50 \%$ of cases. Virtually all co express gamma-herpesvirus. Phenotypically there is prominence of the mixed-cellularity and lymphocyte depleted histopathologic subtypes that define an aggressive clinical course in comparison to other variants. Prior to the induction of cART, median survival was only 1-2 years. Notably the first chemotherapy trial using ABVD (doxorubicin, bleomycin, vinblastine, and dacarbazine) in 21 patients, without treating the viral infection, resulted in a $43 \%$ complete remission rate accompanied by severe haematological toxicities but did not extend median survival with this being 1.5 years matching the negative cases.
\end{abstract}

Significant change accompanied concomitant anti-retroviral therapy that could be given safely even with dose intensive regimens exemplified by BEACOPP (bleomycin, etoposide, doxorubicin, cyclophosphamide, vincristine, procarbazine, and prednisone) in 12 patients or the Stanford V regimen (doxorubicin, vinblastine, mechlorethamine, etoposide, vincristine, bleomycin, prednisone) coupled with involved-field radiation for bulky disease studied in 59 patients. BEACOPP extended overall survival (OS) to $83 \%$ at 2 years. A similar trend was seen 
when using the Stanford V regimen with an OS rate of $51 \%$ at 3 years, disease-free survival (DFS) of $68 \%$ and freedom from progression (FFP) in 60\%. Additional benefits accrued from supportive care with stimulatory peptides such as G-CSF and when combined with bacterial prophylaxis results approached that found in the uninfected reference group. Current consensus holds this particular lymphoma as still among the non-AIDS defining cancers being lung, stomach, liver or anal despite these having recently gained more attention as several of these neoplasms may be occurring more commonly in the era of cART.

While the relative risk of developing a non-AIDS-defining neoplasm in HIV-infected persons on the average is $2-3$ times, the risk for developing HL in HIV-infected cases impressively ranges between 5 and 25 times when compared to the general population. Based on the precedent in which Kaposi sarcoma and the non-Hodgkin lymphomas distinctively alter the course of this retroviral infection in a way indistinguishable from concurrent Hodgkin lymphoma we propose that this entity be similarly regarded and the hypothesis tested in large randomised prospective study.

\section{Introduction}

Acquired immunodeficiency syndrome (AIDS) in the wake of infection with human immunodeficiency virus (HIV) was firstly described in homosexual men living in Los Angeles [1]. This was followed by reports of a markedly higher risk of developing malignancies such as Kaposi's sarcoma (KS) [2] and [3], primary cerebral and systemically occurring non-Hodgkin lymphoma (NHL) [4], [5], [6], [7] and [8] as well as invasive cervical cancer in those harbouring this virus, although the incidence of the latter malignancy has not increased as dramatically [9] and [10].

With the introduction of combination anti-retroviral therapy (cART) in 1996 [11] a modification not only on the morbidity and mortality related to HIV disease but also the spectrum of the different malignancies reported in HIV-infected patients has occurred. An increasing number of other neoplastic disorders including HL, testicular seminoma and lung cancer are still described as non-AIDS defining [12], [13] and [14]. Of note is a long-running Swiss study showing no increase in this particular lymphoma in recent years and also not among persons infected with the human immunodeficiency virus [15]. The same workers find no evidence of any increasing risk with improving immunity.

In this context is the role played by concurrent gamma-herpesvirus coinfection [16]. This distinction may be artificial given that most infected individuals live in sub Saharan Africa (SSA) where no plateau has yet been reached for infection rates [17] with South Africa in the midst of a pandemic having 5.5 million people testing positive [18]. Here malignant disease contributes significantly to morbidity and mortality particularly in this community [19]. The opportunity has therefore been taken extending our previous observations on KS and NHL [20] and [21] to examine a similar possible association for HL. 


\section{Epidemiology}

Almost 20 years ago, Hessol and colleagues were the first researchers observing an excess number of Hodgkin cases among HIV-infected gay men associated with significantly worse outcome particularly higher mortality rates [22]. Cure rates for this lymphoma in the general population is expected to be in the range of 70-80\% [23]. Thus a US based study carried out between 1988 and 1998 demonstrated a 5-year survival of 38\% compared with 78\% in negative matched cohorts [24]. Data from the United States or Europe contrasts with only few studies exploring the situation in the most affected regions.

For example, in a South African survey from 2005, overall HIV prevalence among the adults was $20 \%$ for females and $12 \%$ for males [25]: the risk of developing KS, NHL and HL was, respectively, 50, 6 and 2-fold higher when compared to the negative population. Despite this being the second most common cancer in Africa incidence remains small when in contrast to the 5-25-fold risk observed in western populations [26], [27] and [28]. Even so, none of the other tumour types examined being oral, liver or stomach cancer, melanoma, leukaemias or sarcomas showed a similar increased risk [25]. Furthermore, only few studies have provided information on HIV-infected individuals before progressing to AIDS [26] and [29].

This is important to note as the widespread use of cART since 1996 has not only led to dramatic improvements in immune status and prolonged survival among HIV-infected persons [30] but many may now never develop the overt syndrome. Nevertheless persons only marginally immunosuppressed may still be at excess risk of developing associated malignancies especially with extended survival. A recent study highlights the complex correlation altered immunity and cART in the face of HL [14]. The incidence of this lymphoma increased substantially following an AIDS diagnosis but also, somehow paradoxically, rose over time in association with the introduction of cART. Furthermore, the authors of the study conclude that, among people with this syndrome, the relationship between risk for neoplastic transformation and CD4 count is nonlinear [14].

Confirmation is therefore provided for results from prior studies describing an increasing risk over time subsequent to an AIDS diagnosis [27] and further elevation associated with the introduction of specific drug therapy [26].

\section{Immunbiology, histological subtype and viral coinfection}

The recognition of certain HIV related malignancies correlate with loss of immune control for latent infections with oncogenic viruses such as the human herpesvirus 8 (HHV 8) for KS or Epstein Barr virus (EBV) for selected NHL subtypes [31]. In HIV-infected HL patients EBV positivity can be found in almost all cases [24], [32] and [33], in contrast to the negative cohorts, in which this association has been observed in only $20-50 \%$ depending on histological subtype and age at diagnosis [34]. These findings were confirmed on molecular level by showing the presence of EBV-associated antigens as well as EBV-encoded RNA (EBER) and latent membrane protein-1 (LMP-1) [16] and [24].

Interestingly in the latter cases all histologic subtypes, other than nodular sclerosing, followed a more aggressive course [35] supporting the concept that the presence of both viruses adversely 
affected survival [24]. The mechanism is postulated to reflect the induction of oncogenesis via production of the oncoprotein called LMP-1 released during infection of the lymphocytes [24] and [32]. This might explain the more virulent clinical characteristics and the predominance of the less favourable histologic subtype being mixed cellularity and lymphocyte depleted variants.

Immune reconstitution with cART is causing an increased risk for these tumours by shifting HIV-infected individuals to a level of immunosuppression associated with highest risk [27] and [28]. The Reed Sternberg (RS) cell seems to play a central role in facilitating such complex interactions. It was hypothesized that in severely immunosuppressed HIV-infected individuals usually presenting with CD4 counts below 50/ $\mu 1$ these malignant giant cells cannot recruit lymphocytes and histiocytes, both usually known to produce proinflammatory cytokines, essential survival of this unique tumour cell.

With the increase in CD4 counts during effective anti-retroviral therapy (immune reconstitution) it seems that an overshooting, perturbed and nonlinear way of immunosuppression is needed for the manifestation of disease [28]. Oncogenesis of other HIV related cancers such as cervical, anal or hepatic is associated with specific co-viral infections caused by the human papillomavirus (HPV), hepatitis B or C virus but since even though these neoplasms arise at increased frequency the importance of immunosuppression is less clear [36] and [37].

\section{Clinical findings and presentation}

Hodgkin manifests more aggressively in the HIV-infected population. Bone marrow involvement has been documented in 40-60\% at diagnosis, and may be the initial feature in about $20 \%$ of patients; therefore trephine biopsy should be obligatory [38]. An explanation could be that, in the setting of HIV infection, patients undergo this examination more often for the evaluation of obscure fever, night sweats, fatigue, weight loss as well as pancytopenia [39]. Atypical clinical presentations and unusual pathologic characteristics occur in 30-60\% of HIV-negative individuals even with advanced stages of disease at diagnosis whereas then systemic symptoms are found in more than $70 \%$ once positive [39] and [40].

Furthermore, Poluri et al. [41] noted $100 \%$ of the HIV cases the involvement of head and neck regions in patients compared to $81 \%$ of non-HIV cohorts. Similarly $80 \%$ of cases had stage III and IV HD compared to $45 \%$ of the reference population. Also $75 \%$ had mixed cellularity subtype in contrast to $50 \%$ uninfected individuals. The swollen lymph nodes can get very large and the fever shows a characteristic rise and fall described as Pel-Ebstein, very often accompanied by anaemia and fatigue.

\section{Diagnosis and staging}

Lymph node or tissue biopsy of suspected lesions to confirm presence of the characteristic ReedSternberg cells is routine but should be always accompanied by bone marrow biopsy due to the high likelihood of involvement in patients. In order to minimize late effects without compromising efficacy, risk-adapted strategies, based not only on pre-treatment prognostic factors but also on the results of early restaging positron emission tomography (PET) scans have been recently developed [42]. 
Despite the superiority of the functional imaging, computed tomographic (CT) scans are still routinely used in the initial staging of HL. The reason for this anomaly could be that, although the former is preferred with an advantage in detecting lymphomatous lesions in a further approximately $15 \%$, this "upstaging" effect will not result in a change of treatment strategies based on standard chemotherapy protocols as first-line treatment.

However, the role of more sensitive techniques has become more important in the restaging process after initiation of treatment where it was shown to influence prognosis and treatment outcome [43], [44], [45] and [46]. Although it is widely accepted that a positive interim PET reflects poor prognosis, it is yet unknown whether a change of therapy in these patients will result in improved survival. Also the false positive results await better understanding.

\section{Treatment}

\subsection{Limited}

Defined as having nodal disease, with or without minimal local extension into nearby tissues, on one side of the diaphragm (Ann Arbor stage I or II), absence of B symptoms, no single tumour mass greater than $10 \mathrm{~cm}$ in largest diameter and normal ESR. Three groups have reported the results based on the use of brief exposure to ABVD followed by irradiation for clinical stage IA or IIA non-bulky HL [47], [48] and [49]. The results from these studies favour this approach in minimising the risks for later infertility, premature menopause, leukaemia as well as cardiopulmonary toxicity [50] and [51].

Further reduction in sequelae is possible by avoiding radiotherapy. This step is based on the National Cancer Institute of Canada Clinical Trials Group and the Eastern Cooperative Oncology Group [52] trial comparing ABVD alone with either wide-field radiation for patients with favourable prognostic factors or two cycles followed by similar radiotherapy for those in the category with modest but statistically significant difference in progression-free survival in favour of combined modality therapy but no difference in overall survival.

Therefore such a regimen is currently regarded as an acceptable option for these cases in contrast to bulky early stage disease where additional irradiation remains the standard of care.

\subsection{Advanced}

Here chemotherapy alone has emerged as optimum [50] and [51]. Specifically protocol ABVD given on schedule, without delay and no growth factor support regardless of the absolute neutrophil count on the day of treatment, is advocated. Of note, however, is the use of stimulatory peptide increases bleomycin induced lung toxicity [53] and [54]. Alternatives are Stanford V and escalated BEACOPP [55] and [56] where encouraging results are offset by a marked increase in both short- and long-term toxicities, including infertility, infectious complications and second malignancies so that there is a relevance to use BEACOPP routinely.

However, it does represent a reasonable alternative particularly with high-risk disease as defined by the International Prognostic Score (IPS) [56] and [57]. Despite the CD20 negative immunophenotype in most of the cases several investigators have studied the role of rituximab in the treatment of classical variants. The basis includes direct killing of the Reed-Sternberg cells in 
the $15 \%$ of these cases, depleting B cells in the microenvironment that may be necessary for tumour cell survival and the possibility that these may identify a postulated Hodgkin stem cell [58] and [59].

In the light of evolving experience are trials testing the impact of positivity on the interim PET CT scan in which early inclusion of BEACOPP or ICE containing ifosfamide, carboplatin, etoposide, with or without the use of stem cell transplantation, are attractive but there is currently no proof that this will improve outcome.

\subsection{Relapse}

Recurrence reduces long-term disease-free survival with standard dose chemotherapy to below $20 \%$ [60] and [61]. Exception exists in two subgroups. Firstly those who recur exclusively in the originally involved but unirradiated lymph nodes without B symptoms or extranodal disease [62] and [63] and here wide-field irradiation with or without additional chemotherapy may cure approximately 50\% of patients [63] and [64]. Secondly when this occurs more than 1 year after remission and in the absence of constitutional symptoms repeating the same regimen or using potentially non-cross-resistant chemotherapy with or without irradiation eradicates disease in approximately $35 \%$ of the relapsed patients [60], [65] and [66].

However, both subgroups could be alternatively considered for autologous stem cell transplantation (ASCT). Immunomodulatory agents such as thalidomide or lenalidomide are generally well tolerated and thought to alter the inflammatory environment surrounding the Reed-Sternberg cells or by blocking angiogenesis. Thalidomide, in combination with vinblastine, had a response rate of $36 \%$ in a phase II study of heavily pre-treated patients with Hodgkin lymphoma [67]. Rituximab has documented activity in previously untreated and relapsed lymphocyte predominant Hodgkin lymphoma was shown by the GHSG [68].

In relapse 15 patients treated with four weekly doses of rituximab to achieve a response rate of 94\% with a median time-to-progression of 33 months and a 7-year overall survival of 93\%. The results of two randomised trials led to the establishment of autologous stem cell transplantation as the standard of care for relapses [69]. Presently no survival benefit could be established when employed in first or second relapse so favouring early use to minimize drug exposure and toxicity of previous salvage regimens.

Furthermore, such timing decreases the chance of an inadequate stem cell harvest. Approximately 50\% with chemosensitive relapse, defined as a partial remission or complete remission to salvage therapy, will have a durable remission following this intervention as compared to $20 \%$ with stable disease or a minor response to salvage chemotherapy [69], [70] and [71]. To date no randomised trials have compared the effectiveness of salvage regimens. Thus etoposide with high-dose cytarabine and cisplatinum - ESHAP, ICE, miniBCNU or etoposide, cytosine arabinoside, and melphalan - BEAM, have been used. Recently gemcitabine-containing regimens have shown high response rates with an acceptable side-effect profile [72] and [73]. 


\subsection{Long-term complications}

Over time survival following treatment for Hodgkin's lymphoma has improved significantly [74], [75], [76] and [77] as a consequence of multiagent chemotherapy strategies, more accurate radiotherapy modalities as well as better inclusive management. This is offset by increased risk for developing second primary cancers, infections and cardiovascular disease [78], [79], [80] and [81]. The main cause of death remains disease itself but after 20 years this is negligible [82]. In contrast the relative risks from second primary cancers and cardiovascular disease continue to increase after 10 years.

More than 30 years following diagnosis this pattern is evident especially in those patients treated before the age of 21 but these risks seemed to decrease with age. Emergence of secondary acute leukaemia is strongly associated with the use of alkylating chemotherapy as well as mechlorethamine, which is one component of the MOPP regimen [50]. Since these regimens, having poor survival [79] and [83], are less used there has been fall in the incidence of this late effect [83] and [84]. Splenectomy did not show any increased risk of death arising from infections. One explanation could be that this is due to vaccination against pneumococcal infections usually administered before or immediately after this operation. Instructions on the correct use of antibiotic prophylaxis and treatment are accordingly strongly recommended.

Conversely protracted immunosuppression has been noted after splenectomy combined with radiotherapy and chemotherapy [85] and [86]. Smoking should be discontinued since it was shown to act synergistically with irradiation in the development of lung cancers and cardiovascular disease [87]. Especially in patients who received mediastinal radiotherapy screening for coronary artery disease, beginning 5 years after therapy, is recommended. Standard management of other risk factors including those for premature vascular disease, hypertension or lipid control may help to reduce this absolute excess risk.

\subsection{Management during pregnancy}

Since the vast majority of patients are treated with chemotherapy it is mandatory that staging of a pregnant patient should, besides necessary imaging, consist of a thorough history, physical examination, routine blood tests and a bone marrow biopsy. Examinations such as ultrasonography, chest X-rays with proper shielding or magnetic resonance imaging should provide the desired diagnostic information without increasing the risk of foetal malformation [88] and [89]. Abdominal or pelvic CT are safest avoided during pregnancy giving higher foetal radiation exposure of up to $0.02 \mathrm{~Gy}$.

Positron emission tomography is increasingly favoured in staging. Since ${ }^{18}$ F-FDG or radioglucose can cross the placenta and reach the foetus, it may involve higher radiation exposure than regular CT and its use can therefore not be recommended in this context [90]. However, it can be performed after delivery to assess treatment response with the caveat that breastfeeding should be discontinued for at least $24 \mathrm{~h}$ because this isotope is concentrated both in the breasts and milk [91]. Many cytotoxic agents cross the human placenta and reach the foetus [92] due to their relatively low molecular weight. 
When treating with chemotherapy the physiological changes occurring during pregnancy such as the renal clearance of drugs or increased plasma volume must be considered [93]. These changes might decrease the level of active drug concentrations [93]. Exposure in the first trimester has been associated with a 20\% risk of developing major malformations [92] with this risk being lower with single agents compared to combination regimens accordingly [94] and [95]. If unavoidable in this period, abortion should be considered.

Should termination be unacceptable, for religious reasons, one approach is to initiate single-agent anthracycline or vinca-alkaloid followed by combinations at start of second trimester. A further consideration is that alkylating agents may be less teratogenic than antimetabolites, which are considered to be the most injurious of all cytotoxic drugs used [92], [94] and [95]. There is some evidence suggesting that the ABVD combining adriamycin, bleomycin, vinblastine, dacarbazine is safe during pregnancy [93] and [96] as based on case reports. There is only limited experience regarding effects of MOPP [97] and none with the Stanford V or BEACOPP used in high-risk individuals.

Thus upon diagnosis induction should be initiated promptly with thought given to therapeutic abortion acknowledging potential teratogenic effects in the first trimester as treatment delay has shown to adversely affect survival [98]. Thereafter such intervention is usually not associated with malformations but has shown to increases the risk of foetal or neonatal death, pre-term delivery and low birth weight [92] and [99]. Women can be safely treated comparably to their non-pregnant counterparts [92], [93] and [96] with full doses given [92], [96] and [98].

Exposure to radiotherapy also needs consideration based on size of radiation fields and target dose. Since the most common presentation is supra-diaphragmatic lymphadenopathy, irradiation is feasible in early stage having isolated involvement of neck or axillary lymph nodes [100]. This modality in later gestation correlates with a carcinogenic effect and increased risk for leukaemogenesis or solid tumours within the first decade of life [101]. So far no teratogenic effects have been proven when granulocyte colony-stimulating factor or erythropoietin was needed to overcome treatment related cytopenia [102].

\subsection{The cART era}

Before the introduction of these regimens, median survival of HIV-HL patients was 1.5 years [103] and [104] and so, very clearly, effective intervention is statistically of significant benefit. While the incidence of HIV-HL has increased concurrently with these therapies outcome been improved dramatically, particularly in cases treated concomitantly with chemotherapy and antiretroviral agents [34], [105], [106] and [107]. For example in a study by Gerard et al. [107] a significant increase in disease-free survival of $78 \%$ compared to $61 \%$ could be demonstrated.

Similarly in 57 HIV-related HL patients the impact of cART on outcome was tested on survival to different anti-lymphoma schedules [106]. Those who responded by increasing CD4 cell count of 100/ul or a RNA level below 500 copies/ml had an overall survival rate of $89 \%$ at 2 years compared with $44 \%$ for those who did not meet this criterion or were over 45 years of age [106]. Interestingly, limited data on the treatment with ABVD combined with cART in HIV-related HL, the standard in the non-immunosuppressed population, are available [106], [108] and [109]. 
For example the Spanish GESIDA/GELCAB Group [108] analysed outcome in advanced stage where $87 \%$ achieved CR: at median follow-up of 39 and 47 months, 5-year EFS and OS probabilities were $71 \%$ and $76 \%$, respectively. An immunological response was observed in 56\% and this was also virological in $68 \%$ of all treated patients leading to the conclusion that this regimen is effective and tolerated well. Also that immunosuppressed people should be treated like immunocompetent patients assume adequate support and infectious prophylaxis in the former. One possible explanation for the favourable impact on response and survival to cART is that control of viral replication might decrease the continuous activation of the lymphoid system, which is one of the features involved in AIDS-related lymphomagenesis [110].

Since the introduction of cART, commonly used chemotherapy regimens such as BEACOPP [111], Standford V [112] or VEBEP [113] given concurrently, have yielded encouraging results and all have proven to be feasible and highly effective in this interesting category of lymphoma. When using BEACOPP an overall survival of $83 \%$ was seen at 2 years. With the Standford V regimen 3-year OS, disease-free survival and freedom from progression being 51\%, $68 \%$ and $60 \%$, respectively. Although $69 \%$ of patients were able to complete the treatment without compromising dose intensity grade 3 or 4 neutropenia occurred in $78 \%$ despite the use of G-CSF and some neurotoxicity was noted.

In a separate analysis [114] based on the International Prognostic Score originally developed for Hodgkins [115] it was found that patients with high scores of greater than 2 treated with the Standford V regimen did significantly worse showing a complete response (CR) of $67 \%$ compared to those with scores below 2 where CR was 100\%. Also overall survivals were, respectively, $33 \%$ compared to $76 \%$ at 3 years thereby emphasising the favourable predictive value of low scores less than two.

The VEBEP made up of Vinorelbine, Epirubicin, Bleomycin, Cyclophosphamide and Prednisone study [113], demonstrated a high $75 \%$ complete remission, low relapse rate of $10 \%$ and outstanding overall and disease-free survival probabilities, respectively, of $86 \%$ and $90 \%$ at 2 years on the background of acceptable and moderate toxicity. The BEACOPP regimen so strongly advocated by the German Hodgkin Study Group seems to be highly effective but at the cost of some increased toxicity [111]. In a study of 12 patients only five received concomitant anti-retroviral therapy.

After the completion of six cycles of this regimen nine patients have remained in $\mathrm{CR}$ after a follow up period of 49 months but three patients died within the study period. Two of opportunistic infections during treatment and one to relapse after 2 years. The most commonly observed toxicity was bone marrow suppression as grade 3-4 neutropenia in $75 \%$ of the cohort. Notably plasma levels of retroviral copies increased only moderately or even declined during chemotherapy if cART was given concomitantly.

In a randomised trial full or dose-reduced schedules of epirubicin, bleomycin and vinblastine, together with zidovudine given from the beginning of therapy or started after the third cycle [116], gave an overall survival comparable for both arms but with the rate of opportunistic infection significantly lower in the dose-reduced treatment group. In a prospective nonrandomised trial adding prednisone to EBV to this regimen with zidovudine or dideoxinosyne as anti-retroviral treatment together with G-CSF $74 \%$ of the patients achieved CR. Unfortunately 
the relapse rate was $38 \%$ and median survival was 16 months, with overall survival probability of $32 \%$ and disease-free survival at $53 \%$ at 36 months [117].

The optimal chemotherapy for this viral - lymphoproliferative complex has yet to be defined. Despite the success achieved with the concomitant use of cART, there are also downsides, including drug-related adverse events and the development of resistance [118]. This has led to the view that therapy is best delayed until the CD4 cell count drops below 350/ $\mu 1$ [119]. Significant complications of HIV infection usually occur when the CD4 cell count declines to less than $200 / \mu$ l thus giving rise to the development of opportunistic infections [120].

Newer anti-retroviral regimens with more favourable toxicity and resistance profiles than prior regimens have led to the suggestion of initiating therapy at higher CD4 cell counts [121]. Another important question that needs to be determined is whether earlier introduction directed against the retrovirus at a CD4 cell count above 350/ul would prevent Hodgkin lymphoma is currently unclear. The strong association between these tumours and EBV infection in HIVpositive individuals [24], [32], [33] and [35] suggests that maintenance of higher CD4 counts might suppress the formation of EBV-containing malignant Hodgkin Reed-Sternberg cells.

There are several questions that should be addressed in the future. Up to date, there have been no prospective longitudinal studies assessing the optimal CD4 count at which initiation of therapy would be most beneficial. Furthermore, against this background of treatment outcome shown over the previous years the question arises whether Hodgkin lymphoma should now be elevated to the status of an AIDS-defining entity similar to certain other lymphomas and Kaposi sarcoma.

\section{Concluding comments}

Whereas the incidence of AIDS-related neoplasms have decreased over time, others tumours, referred to as non-AIDS-defining malignancies such as Hodgkin lymphoma (HL), invasive anal carcinoma, cancer of lung or skin have emerged thus challenging HIV-treating clinicians and including all subspecialties. With the introduction of cART over the past decade the focus was predominantly on AIDS related malignancies resulting in a reduction of incidence for Kaposi's sarcoma and non-Hodgkin lymphoma but neglecting certain tumours currently summarized as non-AIDS defining.

In the upcoming years research might profitably focus on some of these non-AIDS defining entities and especially HL which has up to date not been considered as meeting such criteria. Although there is conflicting literature some more recent studies suggest that retrovirally infected individuals are at higher risk for a variety of cancers independent from their CD4 count. There is meanwhile a considerable amount of data demonstrating that the immunosuppression associated with this agent places infected individuals at higher risk for developing lymphomas, Kaposi sarcoma, and cervical cancer.

Some data [30] and [122] suggests that non-AIDS-defining cancers are not associated with a low CD4 count per se and other factors, in combination with presence of the human immunodeficiency virus, such as coinfection with oncogenic agents (HHV8, EBV, HPV), lifestyle or advanced aging may be significant and seem to contribute to the increased risk for a range of neoplasms in this population. 
This applies especially to HL occurring with a significantly, similar to AIDS related cancers, increased risk in HIV-infected individuals when compared with the general population. Specific therapeutic recommendations are lacking for these newly emerging malignancies including this particular lymphoma as well as others non-AIDS defining entities. One of the many urgent questions to be addressed in future is when should therapy be started and, if it was initiated sooner, would the effects decrease the risk of developing non-AIDS-defining malignancies or have an effect on their course?

There is substantial interest to re-evaluate the criteria for best time to first give these drugs on the background of publications. A few studies suggest that maintaining a higher CD4 count and lower HIV RNA level may have some protective effect on non-AIDS-defining cancer. However, there is more and more evidence that with rising CD4 counts the incidence of HL increases in HIV-infected patients whereas the incidence of NHLs decreases. Only few reports have documented the protective effects of anti-retroviral therapy in non-AIDS-defining cancers and no prospective studies have been yet performed.

The only one has so far showed that these were protective and that predictors for the development of apparently unrelated cancers were longer duration of the infection as well as a history of opportunistic events [30]. Interestingly CD4 count below 200/ul at the time of diagnosis was not associated with an increased risk for these entities, suggesting that factors other than a low CD4 cell count may be playing a role in the onset of cancer. In addition, patients not receiving medication or demonstrating higher viral copies were at greater risk for these cancers in general [30].

In contrast, another large linked population based study [122] has shown that other than Hodgkin disease, lung cancer, and testicular seminoma, neoplasms were not strongly associated with the development of immunosuppression. In patients with advanced stage Hodgkin in this setting, treatment with ABVD together with cART is feasible and effective. This supports the concept that patients where the lymphoma is present with virus should be similarly treated as immunocompetent cases presuming only that adequate supportive therapy and anti-infectious prophylaxis are given concomitantly.

Several important questions remain to be clarified in the future. Protocols and clinical trials should focus on certain non-AIDS defining malignancies such as HL which share many common features with the AIDS defining entities. This specific lymphoma could arguably now be considered as AIDS defining with the important caveat that research focus in the future be on how to improve survival and treatment outcome.

\section{Acknowledgements}

Supported by the Haematologic Research and Educational Trust, Chairman's Fund of the AngloAmerican Corporation, The Anthony Taberer - Avontuur Foundation, with grants from Louis Shill and Margaret Ward Foundations. We thank Professor Gary Maartens and Professor Volker Diehl for advice and critical editing of the manuscript. Christine Dölling helped with the bibliographic review, Natasha Trueman typed the manuscript. Appreciation is expressed to our research staff. 


\section{References}

1. M.S. Gottlieb, R. Schroff, H.M. Schanker, J.D. Weisman, P.T. Fan, R.A. Wolf, et al. Pneumocystis carinii pneumonia and mucosal candidiasis in previously healthy homosexual men: evidence of a new acquired cellular immunodeficiency N Engl J Med, 305 (1981), pp. 1425-1431

2. C. Harris, C.B. Small, R.S. Klein, G.H. Friedland, B. Moll, E.E. Emeson, et al. Immunodeficiency in female sexual partners of men with the acquired immunodeficiency syndrome N Engl J Med, 308 (1983), pp. 1181-1184

3. J. Stebbing, M. Bower What can oncologists learn from HIV? Lancet Oncol, 4 (2003), pp. 438-445

4. J.L. Ziegler, A.C. Templeton, C.L. Vogel Kaposi's sarcoma: a comparison of classical, endemic, and epidemic forms Semin Oncol, 11 (1984), pp. 47-52

5. C.C. Boring, R.K. Brynes, W.C. Chan, N. Causey, H.R. Gregory, M.R. Nadel, et al. Increase in highgrade lymphomas in young men Lancet, 1 (1985), pp. 857-859

6. A.M. Levine, P.S. Gill, P.R. Meyer, R.L. Burkes, R. Ross, R.D. Dworsky, et al. Retrovirus and malignant lymphoma in homosexual men JAMA, 254 (1985), pp. 1921-1925

7. J. Stebbing, V. Marvin, M. Bower The evidence-based treatment of AIDS-related non-Hodgkin's lymphoma Cancer Treat Rev, 30 (2004), pp. 249-253

8. C. Thirlwell, D. Sarker, J. Stebbing, M. Bower Acquired immunodeficiency syndrome-related lymphoma in the era of highly active antiretroviral therapy Clin Lymphoma, 4 (2003), pp. 86-92

9. R.M. Phelps, D.K. Smith, C.M. Heilig, L.I. Gardner, C.C. Carpenter, R.S. Klein, et al. Cancer incidence in women with or at risk for HIV Int J Cancer, 94 (2001), pp. 753-757

10. J.J. Goedert, T.R. Coté, P. Virgo, S.M. Scoppa, D.W. Kingma, M.H. Gail, et al. Spectrum of AIDSassociated malignant disorders Lancet, 351 (1998), pp. 1833-1839

11. L. Dal Maso, S. Franceschi Epidemiology of non-Hodgkin lymphomas and other haemolymphopoietic neoplasms in people with AIDS Lancet Oncol, 4 (2003), pp. 110-119

12. T. Powles, M. Bower, G. Daugaard, J. Shamash, A. de Ruiter, M. Johnson, et al. Multicenter study of human immunodeficiency virus-related germ cell tumors J Clin Oncol, 21 (2003), pp. 19221927

13. International Agency for Research on Cancer (IARC). Human immunodeficiency viruses and human T-cell lymphotropic viruses. Lyon: IARC, 1996:261-390. (monographs on the evaluation of carcinogenic risks to humans; Vol. 67).

14. E.A. Engels, R.J. Biggar, H.I. Hall, H. Cross, A. Crutchfield, J.L. Finch, et al. Cancer risk in people infected with human immunodeficiency virus in the United States Int J Cancer, 123 (2008), pp. 187-194

15. G.M. Clifford, M. Rickenbach, M. Lise, L. Dal Maso, M. Battegay, J. Bohlius, et al. Hodgkin lymphoma in the Swiss cohort study Blood, 113 (2009), pp. 5737-5742

16. A. Carbone, E. Cesarman, M. Spina, A. Gloghini, T.F. Schulz HIV-associated lymphomas and gamma-herpesviruses Blood, 113 (2009), pp. 1213-1224

17. UNAIDS. Report on the global AIDS epidemic. Geneva: UNAIDS; 2006.

18. National HIV and syphilis sero-prevalence survey of women attending public health antenatal clinics in South Africa. Pretoria: Department of Health; 2005.

19. J.O. Thomas Acquired immunodeficiency syndrome-associated cancers in Sub-Saharan Africa Semin Oncol, 28 (2001), pp. 198-206

20. G. Sissolak, P. Mayaud AIDS related Kaposi's sarcoma: epidemiological, diagnostic, treatment and control aspects in sub-Saharan Africa Trop Med Int Health, 10 (2005), pp. 981-992

21. G. Sissolak, A. Abayomi, P. Jacobs AIDS defining lymphomas in the era of highly active antiretroviral therapy (HAART)-an African perspective Transfus Apher Sci, 37 (2007), pp. 63-70 
22. N.A. Hessol, M.H. Katz, J.Y. Liu, S.P. Buchbinder, C.J. Rubino, S.D. Holmberg Increased incidence of Hodgkin disease in homosexual men with HIV infection Ann Intern Med, 117 (1992), pp. 309311

23. B. Klimm, R. Schnell, V. Diehl, A. Engert Current treatment and immunotherapy of Hodgkin's lymphoma Haematologica, 90 (2005), pp. 1680-1692

24. S.L. Glaser, C.A. Clarke, M.L. Gulley, F.E. Craig, J.A. DiGiuseppe, R.F. Dorfman, et al. Populationbased patterns of human immunodeficiency virus-related Hodgkin lymphoma in the Greater San Francisco Bay Area, 1988-1998 Cancer, 98 (2003), pp. 300-309

25. O. Shisana, T. Rehle, L. Simbayi, W. Parker, K. Zuma, A. Bhana, et al. South African national HIV prevalence, HIV incidence, behaviour and communications survey Human Sciences Research Council, Cape Town (2005)

26. G.M. Clifford, J. Polesel, M. Rickenbach, L. Dal Maso, O. Keiser, A. Kofler, et al. Cancer risk in the Swiss HIV cohort study: associations with immunodeficiency, smoking, and highly active antiretroviral therapy J Natl Cancer Inst, 97 (2005), pp. 425-432

27. E.A. Engels, R.M. Pfeiffer, J.J. Goedert, P. Virgo, T.S. McNeel, S.M. Scoppa, et al. Trends in cancer risk among people with AIDS in the United States 1980-2002 AIDS, 20 (2006), pp. 1645-1654

28. R.J. Biggar, E.S. Jaffe, J.J. Goedert, A. Chaturvedi, R. Pfeiffer, E.A. Engels Hodgkin lymphoma and immunodeficiency in persons with HIV/AIDS Blood, 108 (2006), pp. 3786-3791

29. A.E. Grulich, Y. Li, A. McDonald, P.K. Correll, M.G. Law, J.M. Kaldor Rates of non-AIDS-defining cancers in people with HIV infection before and after AIDS diagnosis AIDS, 16 (2002), pp. 11551161

30. A. Burgi, S. Brodine, S. Wegner, M. Milazzo, M.R. Wallace, K. Spoone, et al. Incidence and risk factors for the occurrence of non-AIDS-defining cancers among human immunodeficiency virusinfected individuals Cancer, 104 (2005), pp. 1505-1511

31. International Agency for Research on Cancer (IARC). Epstein-Barr virus and Kaposi's sarcoma herpesvirus/human herpesvirus 8. Lyon: IARC; 1997 [Monographs on the evaluation of carcinogenic risks to humans; Vol. 70].

32. R. Dolcetti, M. Boiocchi, A. Gloghini, A. Carbone Pathogenetic and histogenetic features of HIVassociated Hodgkin's disease Eur J Cancer, 37 (2001), pp. 1276-1287

33. M. Boiocchi, V. De Re, A. Gloghini, E. Vaccher, R. Dolcetti, A. Marzotto, et al. High incidence of monoclonal EBV episomes in Hodgkin's disease and anaplastic large-cell KI-1-positive lymphomas in HIV-1-positive patients Int J Cancer, 54 (1993), pp. 53-59

34. M. Spina, M. Berretta, U. Tirelli Hodgkin's disease in HIV Hematol Oncol Clin North Am, 17 (2003), pp. 843-858

35. S.L. Glaser, R.J. Lin, S.L. Stewart, R.F. Ambinder, R.F. Jarrett, P. Brousset, et al. Epstein-Barr virusassociated Hodgkin's disease: epidemiologic characteristics in international data Int J Cancer, 70 (1997), pp. 375-382

36. E.A. Engels, M. Frisch, J.H. Lubin, M.H. Gail, R.J. Biggar, J.J. Goedert Prevalence of hepatitis C virus infection and risk for hepatocellular carcinoma and non-Hodgkin lymphoma in AIDS J Acquir Immune Defic Syndr, 31 (2002), pp. 536-541

37. M. Frisch, R.J. Biggar, J.J. Goedert Human papillomavirus-associated cancers in patients with human immunodeficiency virus infection and acquired immunodeficiency syndrome $\mathrm{J}$ Natl Cancer Inst, 92 (2000), pp. 1500-1510

38. E. Vaccher, M. Spina, U. Tirelli Clinical aspects and management of Hodgkin's disease and other tumours in HIV-infected individuals Eur J Cancer, 37 (2001), pp. 1306-1315

39. A.M. Levine Hodgkin's disease in the setting of human immunodeficiency virus infection J Natl Cancer Inst Monogr, 23 (1998), pp. 37-42 
40. J.M. Andrieu, S. Roithmann, J.M. Tourani, R. Levy, B. Desablens, C. le Maignan, et al. Hodgkin's disease during HIV1 infection: the French registry experience. French registry of HIV-associated tumors Ann Oncol, 4 (1993), pp. 635-641

41. A. Poluri, K.G. Shah, J.F. Carew, A.R. Shaha, G. Har-El, F.E. Lucente, et al. Hodgkin's disease of the head and neck in human immunodeficiency virus-infected patients Am J Otolaryngol, 23 (2002), pp. 12-16

42. V. Diehl Hodgkin's disease-from pathology specimen to cure N Engl J Med, 357 (2007), pp. 1968-1971

43. M. Hutchings, A. Loft, M. Hansen, L.M. Pedersen, T. Buhl, J. Jurlander, et al. FDG-PET after two cycles of chemotherapy predicts treatment failure and progression-free survival in Hodgkin lymphoma Blood, 107 (2006), pp. 52-59

44. A. Gallamini, L. Rigacci, F. Merli, L. Nassi, A. Bosi, T. Capodanno, et al.The predictive value of positron emission tomography scanning performed after two courses of standard therapy on treatment outcome in advanced stage Hodgkin's disease Haematologica, 91 (2006), pp. 475-481

45. A. Gallamini, M. Hutchings, L. Rigacci, L. Specht, F. Merli, M. Hansen, et al. Early Interim 2[18F]Fluoro-2-deoxy-d-glucose positron emission tomography is prognostically superior to international prognostic score in advanced-stage Hodgkin's lymphoma: a report from a joint Italian-Danish study J Clin Oncol, 25 (2007), pp. 3746-3752

46. R. Advani, L. Maeda, P. Lavori, A. Quon, R. Hoppe, S. Breslin, et al. Impact of positive positron emission tomography on prediction of freedom from progression after Stanford $V$ chemotherapy in Hodgkin's disease J Clin Oncol, 25 (2007), pp. 3902-3907

47. G. Bonadonna, V. Bonfante, S. Viviani, A. Di Russo, F. Villani, P. ValagussaABVD plus subtotal nodal versus involved-field radiotherapy in early-stage Hodgkin's disease: long-term results J Clin Oncol, 22 (2004), pp. 2835-2841

48. A. Engert, J. Franklin, H.T. Eich, C. Brillant, S. Sehlen, C. Cartoni, et al. Two cycles of doxorubicin, bleomycin, vinblastine, and dacarbazine plus extended-field radiotherapy is superior to radiotherapy alone in early favorable Hodgkin's lymphoma: final results of the GHSG HD7 trial J Clin Oncol, 25 (2007), pp. 3495-3502

49. J.M. Connors State-of-the-art therapeutics: Hodgkin's lymphoma J Clin Oncol, 23 (2005), pp. 6400-6408

50. D.B. Duggan, G.R. Petroni, J.L. Johnson, J.H. Glick, R.I. Fisher, J.M. Connors, et al. Randomized comparison of ABVD and MOPP/ABV hybrid for the treatment of advanced Hodgkin's disease: report of an intergroup trial J Clin Oncol, 21 (2003), pp. 607-614

51. G.P. Canellos, J.R. Anderson, K.J. Propert, N. Nissen, M.R. Cooper, E.S. Henderson, et al. Chemotherapy of advanced Hodgkin's disease with MOPP, ABVD, or MOPP alternating with ABVD N Engl J Med, 327 (1992), pp. 1478-1484

52. R.M. Meyer, M.K. Gospodarowicz, J.M. Connors, R.G. Pearcey, A. Bezjak, W.A. Wells, et al. Randomized comparison of ABVD chemotherapy with a strategy that includes radiation therapy in patients with limited-stage Hodgkin's lymphoma: national cancer institute of Canada clinical trials group and the eastern cooperative oncology group J Clin Oncol, 23 (2005), pp. 4634-4642

53. A.M. Evens, J. Cilley, T. Ortiz, M. Gounder, N. Houn, A. Rademaker, et al. G-CSF is not necessary to maintain over $99 \%$ dose-intensity with ABVD in the treatment of Hodgkin lymphoma: low toxicity and excellent outcomes in a 10-year analysis Br J Haematol, 137 (2007), pp. 545-552

54. W.G. Martin, K.M. Ristow, T.M. Habermann, J.P. Colgan, T.E. Witzig, S.M. Ansell Bleomycin pulmonary toxicity has a negative impact on the outcome of patients with Hodgkin's lymphoma J Clin Oncol, 23 (2005), pp. 7614-7620

55. S.J. Horning, R.T. Hoppe, S. Breslin, N.L. Bartlett, B.W. Brown, S.A. Rosenberg Stanford V and radiotherapy for locally extensive and advanced Hodgkin's disease: mature results of a prospective clinical trial J Clin Oncol, 20 (2002), pp. 630-637 
56. V. Diehl, J. Franklin, M. Pfreundschuh, B. Lathan, U. Paulus, D. Hasenclever, et al. Standard and increased-dose BEACOPP chemotherapy compared with COPP-ABVD for advanced Hodgkin's disease N Engl J Med, 348 (2003), pp. 2386-2395

57. D. Hasenclever, V. Diehl, J.O. Armitage, D. Assouline, M. Björkholm, E. Brusamolino, et al. A prognostic score for advanced Hodgkin's disease N Engl J Med, 339 (1998), pp. 1506-1514

58. Wedgwood AR, Fanale MA, Fayad LE, McLaughlin P, Hagemeister FB, Pro B, et al. Rituximab + ABVD improves event-free survival (EFS) in patients with classical Hodgkin lymphoma in all international prognostic score (IPS) groups and in patients who have PET positive disease after 2-3 cycles of therapy. Blood 2007;110:71a [abstract 215].

59. Jones RJ, Lin L, Gocke C, Hensley K, Siedner M, Barber JP, et al. Clonotypic B cells circulate in Hodgkin's lymphoma (HL). Blood 2006;108:143a [Abstract 470].

60. D.L. Longo, P.L. Duffey, R.C. Young, S.M. Hubbard, D.C. Ihde, E. Glatstein, et al. Conventionaldose salvage combination chemotherapy in patients relapsing with Hodgkin's disease after combination chemotherapy: the low probability for cure J Clin Oncol, 10 (1992), pp. 210-218

61. V. Bonfante, A. Santoro, S. Viviani, L. Devizzi, M. Balzarotti, F. Soncini, et al. Outcome of patients with Hodgkin's disease failing after primary MOPP-ABVD J Clin Oncol, 15 (1997), pp. 528-534

62. M. Roach, N. Brophy, R. Cox, A. Varghese, R.T. Hoppe Prognostic factors for patients relapsing after radiotherapy for early-stage Hodgkin's disease J Clin Oncol, 8 (1990), pp. 623-629

63. P. Mauch, N. Tarbell, A. Skarin, D. Rosenthal, H. Weinstein Wide-field radiation therapy alone or with chemotherapy for Hodgkin's disease in relapse from combination chemotherapy J Clin Oncol, 5 (1987), pp. 544-549

64. M. Roach, D.S. Kapp, S.A. Rosenberg, R.T. Hoppe Radiotherapy with curative intent: an option in selected patients relapsing after chemotherapy for advanced Hodgkin's disease J Clin Oncol, 5 (1987), pp. 550-555

65. A. Lohri, M. Barnett, R.N. Fairey, S.E. O’Reilly, G.L. Phillips, D. Reece, et al. Outcome of treatment of first relapse of Hodgkin's disease after primary chemotherapy: identification of risk factors from the British Columbia experience 1970 to 1988 Blood, 77 (1991), pp. 2292-2298

66. A.R. Yuen, S.A. Rosenberg, R.T. Hoppe, J.D. Halpern, S.J. Horning Comparison between conventional salvage therapy and high-dose therapy with autografting for recurrent or refractory Hodgkin's disease Blood, 89 (1997), pp. 814-822

67. J. Kuruvilla, K. Song, P. Mollee, T. Panzarella, J. McCrae, T. Nagy, et al. A phase II study of thalidomide and vinblastine for palliative patients with Hodgkin's lymphoma Hematology, 11 (2006), pp. 25-29

68. H. Schulz, U. Rehwald, F. Morschhauser, T. Elter, C. Driessen, T. Rüdiger, et al. Rituximab in relapsed lymphocyte-predominant Hodgkin lymphoma: long-term results of a phase 2 trial by the German Hodgkin Lymphoma Study Group (GHSG) Blood, 111 (2008), pp. 109-111

69. D.C. Linch, D. Winfield, A.H. Goldstone, D. Moir, B. Hancock, A. McMillan, et al. Dose intensification with autologous bone-marrow transplantation in relapsed and resistant Hodgkin's disease: results of a BNLI randomised trial Lancet, 341 (1993), pp. 1051-1054

70. A. Sureda, M. Constans, A. Iriondo, R. Arranz, M.D. Caballero, M.J. Vidal, et al. Prognostic factors affecting long-term outcome after stem cell transplantation in Hodgkin's lymphoma autografted after a first relapse Ann Oncol, 16 (2005), pp. 625-633

71. C.H. Moskowitz, T. Kewalramani, S.D. Nimer, M. Gonzalez, A.D. Zelenetz, J. Yahalom Effectiveness of high dose chemoradiotherapy and autologous stem cell transplantation for patients with biopsy-proven primary refractory Hodgkin's disease Br J Haematol, 124 (2004), pp. 645-652

72. N.L. Bartlett, D. Niedzwiecki, J.L. Johnson, J.W. Friedberg, K.B. Johnson, K. van Besien, et al. Gemcitabine, vinorelbine, and pegylated liposomal doxorubicin (GVD), a salvage regimen in relapsed Hodgkin's lymphoma: CALGB 59804 Ann Oncol, 18 (2007), pp. 1071-1079 
73. J. Kuruvilla, T. Nagy, M. Pintilie, R. Tsang, A. Keating, M. Crump Similar response rates and superior early progression-free survival with gemcitabine, dexamethasone, and cisplatin salvage therapy compared with carmustine, etoposide, cytarabine, and melphalan salvage therapy prior to autologous stem cell transplantation for recurrent or refractory Hodgkin lymphoma Cancer, 106 (2006), pp. 353-360

74. R. Somers, P. Carde, M. Henry-Amar, M. Tarayre, J. Thomas, A. Hagenbeek, et al. A randomized study in stage IIIB and IV Hodgkin's disease comparing eight courses of MOPP versus an alteration of MOPP with ABVD: a European organization for research and treatment of cancer lymphoma cooperative group and groupe Pierre-et-Marie-Curie controlled clinical trial J Clin Oncol, 12 (1994), pp. 279-287

75. M. Loeffler, O. Brosteanu, D. Hasenclever, M. Sextro, D. Assouline, A.A. Bartolucci, et al. Metaanalysis of chemotherapy versus combined modality treatment trials in Hodgkin's disease. International database on Hodgkin's disease overview study group J Clin Oncol, 16 (1998), pp. 818-829

76. C. Fermé, C. Sebban, C. Hennequin, M. Diviné, P. Lederlin, J. Gabarre, et al. Comparison of chemotherapy to radiotherapy as consolidation of complete or good partial response after six cycles of chemotherapy for patients with advanced Hodgkin's disease: results of the Groupe d'Etudes des Lymphomes de l'Adulte H89 trial Blood, 95 (2000), pp. 2246-2252

77. S.J. Horning, J. Williams, N.L. Bartlett, J.M. Bennett, R.T. Hoppe, D. Neuberg, et al. Assessment of the Stanford V regimen and consolidative radiotherapy for bulky and advanced Hodgkin's disease: eastern cooperative oncology group pilot study E1492 J Clin Oncol, 18 (2000), pp. 972980

78. S.L. Hancock, R.T. Hoppe Long-term complications of treatment and causes of mortality after Hodgkin's disease Semin Radiat Oncol, 6 (1996), pp. 225-242

79. C. Metayer, C.F. Lynch, E.A. Clarke, B. Glimelius, H. Storm, E. Pukkala, et al. Second cancers among long-term survivors of Hodgkin's disease diagnosed in childhood and adolescence J Clin Oncol, 18 (2000), pp. 2435-2443

80. F.E. van Leeuwen, W.J. Klokman, M.B. Veer, A. Hagenbeek, A.D. Krol, U.A. Vetter, et al. Longterm risk of second malignancy in survivors of Hodgkin's disease treated during adolescence or young adulthood J Clin Oncol, 18 (2000), pp. 487-497

81. G.M. Dores, C. Metayer, R.E. Curtis, C.F. Lynch, E.A. Clarke, B. Glimelius, et al. Second malignant neoplasms among long-term survivors of Hodgkin's disease: a population-based evaluation over 25 years J Clin Oncol, 20 (2002), pp. 3484-3494

82. B.M. Aleman, A.W. van den Belt-Dusebout, W.J. Klokman, M.B. van't Veer, H. Bartelink, F.E. van Leeuwen Long-term cause-specific mortality of patients treated for Hodgkin's disease J Clin Oncol, 21 (2003), pp. 3431-3439

83. van Leeuwen FE, Swerdlow AJ, Valagussa $P$, Tucker MA. Second cancers after treatment of Hodgkin's disease. In: Mauch PM, Armitage JO, Diehl V, Hoppe RT, Weiss LM, editors. Hodgkin's disease. Philadelphia: Lippincott Williams and Wilkins; 1999: 607-32.

84. J.M. Kaldor, N.E. Day, E.A. Clarke, F.E. van Leeuwen, M. Henry-Amar, M.V. Fiorentino, et al. Leukemia following Hodgkin's disease N Engl J Med, 322 (1990), pp. 7-13

85. L.J. Bruce, B.W. Hancock Immunity in Hodgkin's disease: status after 10 years' remission Br J Cancer, 62 (1990), pp. 324-325

86. R.T. Hoppe, Z.Y. Fuks, S. Strober, H.S. Kaplan The long term effects of radiation of T and B lymphocytes in the peripheral blood after regional irradiation Cancer, 40 (1977), pp. 2071-2078

87. F.E. van Leeuwen, W.J. Klokman, M. Stovall, A. Hagenbeek, A.W. van den Belt-Dusebout, R. Noyon, et al. Roles of radiotherapy and smoking in lung cancer following Hodgkin's disease J Natl Cancer Inst, 87 (1995), pp. 1530-1537 
88. I. Kawabata, Y. Takahashi, S. Iwagaki, T. Tamaya MRI during pregnancy J Perinat Med, 31 (2003), pp. 449-458

89. D. Levine Obstetric MRI J Magn Reson Imaging, 24 (2006), pp. 1-15

90. R.J. Hicks, D. Binns, M.G. Stabin Pattern of uptake and excretion of 18 F-FDG in the lactating breast J Nucl Med, 42 (2001), pp. 1238-1242

91. H. Benveniste, J.S. Fowler, W.D. Rooney, D.H. Moller, W.W. Backus, D.A. Warner, et al. Maternal-fetal in vivo imaging: a combined PET and MRI study J Nucl Med, 44 (2003), pp. 15221530

92. B. Weisz, D. Meirow, E. Schiff, M. Lishner Impact and treatment of cancer during pregnancy Exper Rev Anticancer Ther, 4 (2004), pp. 889-902

93. E. Cardonick, A. lacobucci Use of chemotherapy during human pregnancy Lancet Oncol, 5 (2004), pp. 283-291

94. D.C. Doll, Q.S. Ringenberg, J.W. Yarbro Management of cancer during pregnancy Arch Intern Med, 148 (1998), pp. 2058-2064

95. T. Randall National registry seeks scarce data on pregnancy outcomes during chemotherapy JAMA, 269 (1993), p. 323

96. A. Aviles, N. Neri Hematological malignancies and pregnancy: a final report of 84 children who received chemotherapy in utero Clin Lymphoma, 2 (2001), pp. 173-177

97. B. Weisz, E. Schiff, M. Lishner Cancer in pregnancy: maternal and fetal implications Hum Reprod Update, 7 (2001), pp. 384-393

98. M. Lishner, D. Zemlickis, P. Degendorfer, T. Panzarella, S.B. Sutcliffe, G. Koren Maternal and foetal outcome following Hodgkin's disease in pregnancy Br J Cancer, 65 (1992), pp. 114-117

99. D. Zemlickis, M. Lishner, P. Degendorfer, T. Panzarella, S.B. Sutcliffe, G. Koren Fetal outcome after in utero exposure to cancer chemotherapy Arch Intern Med, 152 (1992), pp. 573-576

100. E. Fenig, M. Mishaeli, Y. Kalish, M. Lishner Pregnancy and radiation Cancer Treat Rev, 27 (2001), pp. 1-7

101. H.B. Kal, H. Struikmans Radiotherapy during pregnancy: fact and fiction Lancet Oncol, 6 (2005), pp. 328-333

102. S. Sifakis, E. Angelakis, E. Vardaki, Y. Koumantaki, I. Matalliotakis, E. Koumantakis Erythropoietin in the treatment of iron deficiency anemia during pregnancy Gynecol Obstet Invest, 51 (2001), pp. $150-156$

103. M.C. Cheung, L. Pantanowitz, B.J. Dezube AIDS-related malignancies: emerging challenges in the era of highly active antiretroviral therapy Oncologist, 10 (2005), pp. 412-426

104. A.M. Levine, P. Li, T. Cheung, A. Tulpule, J. Von Roenn, R.N. Nathwani, et al. Chemotherapy consisting of doxorubicin, bleomycin, vinblastine, and dacarbazine with granulocyte-colonystimulating factor in HIV-infected patients with newly diagnosed Hodgkin's disease: a prospective, multi-institutional AIDS clinical trials group study (ACTG 149) J Acquir Immune Defic Syndr, 24 (2000), pp. 444-450

105. P.Y. Tanaka, V.P. Pessoa Jr, L.F. Pracchia, V. Buccheri, D.A. Chamone, E.E. Calore Hodgkin lymphoma among patients infected with HIV in post-HAART era Clin Lymphoma Myeloma, 7 (2007), pp. 364-368

106. C. Hoffmann, K.U. Chow, E. Wolf, G. Faetkenheuer, H.J. Stellbrink, E. van Lunzen, et al. Strong impact of highly active antiretroviral therapy on survival in patients with human immunodeficiency virus-associated Hodgkin's disease Br J Haematol, 125 (2004), pp. 455-462

107. L. Gerard, L. Galicier, E. Boulanger, L. Quint, M.G. Lebrette, E. Mortier, et al. Improved survival in HIV-related Hodgkin's lymphoma since the introduction of highly active antiretroviral therapy AIDS, 17 (2003), pp. 81-87

108. B. Xicoy, R.M. Ribera, P. Miralles, J. Berenguer, R. Rubio, B. Mahillo, et al. Results of treatment with doxorubicin, bleomycin, vinblastine and dacarbazine and highly active antiretroviral 
therapy in advanced stage, human immunodeficiency virus-related Hodgkin's lymphoma. GESIDA group and GELCAB group Haematologica, 92 (2007), pp. 191-198

109. R. Gastaldi, P. Martino, G. Gentile, V. Picardi, M.S. De Propios, M.F. Pirillo, et al. Hodgkin's disease in HIV-infected patients: report of eight cases usefully treated with doxorubicin, bleomycin, vinblastine and dacarbazine (ABVD) plus granulocyte colony-stimulating factor Ann Oncol, 13 (2002), pp. 1158-1160

110. G. Gaidano, A. Carbone, R. Dalla-Favera Pathogenesis of AIDS-related lymphomas Am J Pathol, 152 (1998), pp. 623-630

111. P. Hartmann, U. Rehwald, B. Salzberger, C. Franzen, M. Sieber, A. Wöhrmann, et al. BEACOPP therapeutic regimen for patients with Hodgkin's disease and HIV infection Ann Oncol, 14 (2003), pp. 1562-1569

112. M. Spina, J. Gabarre, G. Rossi, M. Fasan, C. Chiantarelli, E. Nigra, et al. Stanford V and concomitant HAART in 59 patients with Hodgkin's disease and HIV infection Blood, 100 (2002), pp. 1984-1988

113. M. Spina, G. Rossi, A. Antinori, B. Allione, M. Fasan, G. Rizzardini, et al. VEBEP regimen and highly active antiretroviral therapy (HAART) in patients with HD and HIV Infection (HD-HIV) Blood, 106 (2005), p. 100a

114. M. Spina, A. Re, E. Vaccher, J. Gabarre, U. Tirelli High international prognostic score predicts a worse outcome for patients with Hodgkin's disease and HIV infection: results of a prospective study with Stanford V regimen Ann Oncol, 14 (2003), pp. 655-656

115. D. Hasenclever, V. Diehl A prognostic score for advanced Hodgkin's disease N Engl J Med, 339 (1998), pp. 1506-1514

116. D. Errante, J. Gabarre, A.L. Ridolfo, G. Rossi, A.M. Nosari, C. Gisselbrecht, et al. Hodgkin's disease in 35 patients with HIV infection: an experience with epirubicin, bleomycin, vinblastine and prednisone chemotherapy in combination with antiretroviral therapy and primary use of G-CSG Ann Oncol, 10 (1999), pp. 189-195

117. D. Errante, U. Tirelli, R. Gastaldi, D. Milo, A.M. Nosari, G. Rossi, et al. Combined antineoplastic and anti-retroviral therapy for patients with Hodgkin's disease and human immunodeficiency virus infection. A prospective study of 17 patients. The Italian cooperative group on AIDS and tumors (GICAT) Cancer, 73 (1994), pp. 437-444

118. Sissolak G, Andrews S, Abayomi A, Jacobs P. Haematopoietic and cardiovascular complications in patients infected with the human immunodeficiency virus Resources Cardiovasc Sci 2009; 17p.

119. S.M. Hammer, M.S. Saag, M. Schechter, J.S. Montaner, R.T. Schooley, D.M. Jacobsen, et al. Treatment for adult HIV infection: 2006 recommendations of the International AIDS society-USA panel JAMA, 296 (2006), pp. 827-843

120. J.W. Mellors, A. Munoz, J.V. Giorgi, J.W. Margolick, C.J. Tassoni, P. Gupta, et al. Plasma viral load and CD4 + lymphocytes as prognostic markers of HIV-1 infection Ann Intern Med, 126 (1997), pp. 946-954

121. J.E. Gallant Should antiretroviral therapy be started earlier? Curr HIV/AIDS Rep, 4 (2007), pp. 5359

122. S.M. Mbulaiteye, R.J. Biggar, J.J. Goedert, E.A. Engels Immune deficiency and risk for malignancy among persons with AIDS J Acquir Immune Defic Syndr, 32 (2003), pp. 527-533 